\title{
Associations between social skills and burnout dimensions in medical residents
}

\author{
Associações entre habilidades sociais e dimensões \\ de burnout em médicos residentes
}

\author{
Karina PEREIRA-LIMA \\ Sonia Regina LOUREIRO
}

\begin{abstract}
Medical residency has been considered a stressful, overwhelming period, which can contribute to the development of burnout syndrome. Given the importance of interpersonal interactions for the professional practice of medicine, studies addressing protective factors against burnout focusing on social skills are needed. The objective of the present study was to investigate the associations between social skills and burnout dimensions in medical residents. A total of 305 residents were evaluated using the Inventário de Habilidades Sociais (Social Skills Inventory) and the Inventário da Sindrome de Burnout (Burnout Syndrome Inventory). Significant associations were found between all social skills factors and at least one burnout dimension; odds ratio results indicated a protective relationship, in which the residents with an elaborate repertoire of social skills were less likely to have indicators of burnout. Considering the fact that social skills can be learned, these results can contribute to the introduction of preventive measures.
\end{abstract}

Keywords: Burnout, professional; Internship and residency; Social skills.

\section{Resumo}

A residência médica é um período com características reconhecidamente estressantes que podem contribuir para o desenvolvimento da síndrome de burnout. Configuram-se como lacuna da literatura estudos que abordem condições de proteção ao burnout, colocando em foco as habilidades sociais, dada a relevância das interações interpessoais para o exercício profissional do médico. Objetivou-se verificar as associações entre o repertório de habilidades sociais e as dimensões de burnout de médicos residentes. Trezentos e cinco residentes foram avaliados por meio dos seguintes instrumentos: Inventário de Habilidades Sociais e Inventário da Síndrome de Burnout. Foram verificadas associações significativas de todos os fatores de habilidades sociais com pelo menos uma dimensão de burnout, com valores de odds ratio sugestivos de uma relação de proteção, sendo que residentes com um repertório elaborado de habilidades sociais apresentaram menos chances de apresentarem indicadores de burnout. Considerando-se que habilidades sociais podem ser aprendidas, esses dados podem contribuir para a proposição de medidas preventivas.

Palavras-chave: Esgotamento profissional; Internato e residência; Habilidades sociais.

\footnotetext{
$\nabla \nabla \nabla$

1 Universidade de São Paulo, Faculdade de Medicina de Ribeirão Preto, Departamento de Neurociências e Ciências do Comportamento. R. Tenente Catão Roxo, 2650, 14051-140, Ribeirão Preto, SP, Brasil. Correspondência para/Correspondence to: K. PEREIRA-LIMA. E-mail: <pereiralima.k@gmail.com>.

Article based on the master's thesis of K. PEREIRA-LIMA, entitled "Associações e comparações entre burnout, ansiedade, depressão e habilidades sociais de residentes médicos de diferentes áreas”. Universidade de São Paulo, 2014.

Acknowledgments: Fundação de Amparo à Pesquisa do Estado de São Paulo (Process no 2012/02987-4), Coordenação de Aperfeiçoamento de Pessoal de Nivel Superior, and Conselho Nacional de Desenvolvimento Científico e Tecnológico.
} 
Empirical studies have shown that a satisfactory repertoire of social skills has a positive impact on the quality of social relationships, contributing to a more effective adaption at different stages of human development (Carneiro \& Falcone, 2013; Cia \& Barham, 2009; Hohendorff, Couto, \& Prati, 2013; Soares, Francischetto, Peçanha, Miranda, \& Dutra, 2013). According to Del Prette and Del Prette (2013), social skills can be defined as different classes of behaviors in the individuals' repertoire contributing to socially competent performance, which implies functionality and consistency between the individual's thoughts and feelings.

With regard to professional practice, a number of interpersonal skills are increasingly required, such as people management, teamwork, leadership, problem solving, negotiation, and others that can contribute to better performance of individuals in different professional activities (Bolsoni-Silva, Loureiro, Rosa, \& Oliveira, 2010; Del Prette \& Del Prette, 2013).

It can be said that most medical practice activities involve interactions between doctors and other people (patients, staff, colleagues), which suggests that good social skills can contribute to successful professional practice (Pereira-Lima \& Loureiro, 2015). Studies with medical residents and medical students have identified that the presence of an elaborate repertoire of social skills is associated with lower levels of stress indicators (Furtado, Falcone, \& Clark, 2003), daytime sleepiness (Kloster, Perotta, Hauer, Paro, \& Tempski, 2013), and mental health problems (Pereira-Lima \& Loureiro, 2015).

Doctors who are starting a new medical practice, such as residents, often face many technical and interpersonal challenges. Residency training is considered a stressful period since it involves long working hours, sleep deprivation, and great responsibility for the lives of others, and therefore some stress seems inevitable (Thomas, 2004). Accordingly, burnout syndrome in medical residents has received increased attention in recent years, given its prevalence among these professionals and serious damages and disruptions associated with it (Doolittle \& Windish, 2015;
Jennings \& Slavin, 2015; Lebensohn et al., 2013; Oliveira Júnior et al., 2013; Pereira-Lima \& Loureiro, 2015; Thomas, 2004; West, Shanafelt, \& Kolars, 2011).

Burnout is an occupational syndrome that involves many somatic, psychological, and behavioral symptoms that include three dimensions: emotional exhaustion, which is characterized by a state of severe mental and physical exhaustion and lack of energy to carry out work activities; depersonalization or cynicism, which refers to detached responses to other people at work, resulting in increasingly cold and impersonal relationships; and reduced sense of personal accomplishment or efficacy, which is related to high job dissatisfaction, reduction of efficiency and productivity at work, and negative self-evaluation (Benevides-Pereira, 2002; Maslach, Schaufeli, \& Leiter, 2001). These characteristics confirm the multidimensional nature of this syndrome (Maslach et al., 2001).

Burnout syndrome in medical residents has been associated with many negative impacts on them and on their patients, such as self-reporting of medical errors (Oliveira Júnior et al., 2013; Prins et al., 2009; West, Tan, Habermann, Sloan, \& Shanafelt, 2009); deterioration in the quality of patient care (Shanafelt, Bradley, Wipf, \& Back, 2002); suicidal ideation (Dyrbye \& Shanafelt, 2016; van der Heijden, Dillingh, Bakker, \& Prins, 2008), and mental health problems (Dyrbye \& Shanafelt, 2016; Mariños, Otero, Málaga, \& Tomateo, 2011; Oliveira Júnior et al., 2013; Pereira-Lima \& Loureiro, 2015).

There is a lack of studies on the personal factors that may prevent the onset of the syndrome and act as potential protective factors. This gap draws attention to the interest in social skills due to the importance of interpersonal interactions related to medical practice. From this perspective, the present study contributes to bridge this gap by focusing on multispecialty residents.

Therefore, this study aimed at investigating the associations between social skills and burnout dimensions in medical residents. 
Method

\section{Participants}

Based on a search conducted on a database provided by the Human Resources department of the Hospital das Clínicas da Faculdade de Medicina de Ribeirão Preto da Universidade de São Paulo (Clinics Hospital of Ribeirão Preto, University of São Paulo) in 2012, the sample size was calculated considering a minimum attrition rate of $25 \%, 95 \%$ confidence interval, and a maximum margin of error of $5 \%$, resulting in a minimum of 193 participants to ensure the sample was representative of the medical residents of that hospital. Four hundred participants were selected using convenience sampling, according to the following criteria: (a) Inclusion: residents enrolled in the residency program for at least six months; (b) Exclusion: residents who had completed residency training in a specialty other than the specialty required as a prerequisite in the current program; those who were enrolled in subspecialty program or were fellow residents; and foreigners who had been in Brazil for less than two years.

The study sample was composed of 305 medical residents (response rate of $76.25 \%$ ) in 41 specialties. Of these 305 participants, 146 (47.87\%) were female, and the average age was 28 years (SD = 2.53); 169 (58.69\%) were enrolled in clinical area programs and $126(41.31 \%)$ were in surgical area programs; 156 (51.15\%) were in the initial years of the training (first and second years); and $149(48.85 \%)$ were in the final years of medical residency (third to fifth years).

\section{Instruments}

Inventário de Habilidades Sociais

(IHS, Social Skills Inventory) (Del

Prette \& Del Prette, 2001).

This is a Brazilian self-report instrument designed to assess social skills required in different daily interpersonal situations involving a number of different contexts and interlocutors (Del Prette \& Del Prette, 2001).

This instrument has 38 items; each item presents a situation, and the respondents are asked to indicate how often they react as described in the options given using a 5 -point Likert scale ranging from never or rarely ("in every ten situations like this, I react that way 2 times at most") to almost always or always ("in every ten situations like this, I react that way 9-10 times").

The total score and factor scores can be calculated, and interpretation of data derived from the scale is based on the respondent's answer in terms of norm-referenced scores reported as percentile ranks compared to its reference subgroup of the same gender. With regard to the factor scores, the items were grouped into five factors, as reported by Del Prette and Del Prette (2013): (I) Factor 1: coping and self-assertion with risk; (II) Factor 2: self-assertion in the expression of positive affection; (III) Factor 3: conversation and social confidence; (IV) Factor 4: self-exposure to strangers and new situations; (V) Factor 5: self-control over aggressiveness.

The psychometric properties of this instrument were verified by Bandeira, Costa, Del Prette, Del Prette, and Grek-Carneiro (2000), and the test was found to have high test-retest reliability $(r=0.90, p<0.001)$ and the concurrent validity of 0.79 ( $p<0.01)$, which was assessed by comparing it with the Rathus Assertiveness Scale. With regard to the internal consistency of this instrument, Barreto, Del Prette and Del Prette (1998) found Cronbach's alpha of 0.75 , and the factor coefficients ranged between $\alpha=0.74$ and $\alpha=0.96$, explaining $92.75 \%$ of the total variance. These data show the psychometric adequacy of the instrument.

\section{Inventário da Síndrome de Burnout (ISB, Burnout Syndrome Inventory) (Benevides-Pereira, 2007)}

A Brazilian instrument designed to assess the burnout syndrome in any occupation. It is composed of 35 items distributed into two parts (16 and 19 
items, respectively). The first part assesses the organizational factors which are reported in the literature as triggers or modulators of occupational stress and consequently of burnout (Benevides-Pereira, 2007). The second part assesses four dimensions of the syndrome: Emotional Exhaustion (EE), Emotional Detachment (ED), Dehumanization (Dh) and Professional Accomplishment (PA) (Benevides-Pereira, 2007).

The second part of the instrument was used in the present study, and its items consist of statements to be answered on a 5-point Likert scale ranging from 0 to 4 (from never to every day) (Benevides-Pereira, 2007). Scores higher than 9 for $E E$, six for ED, 7 for Dh, and lower than 10 for PA are indicative of problems.

The standardization sample of the instrument was composed of 1505 participants of both genders aged 18-73 years $(M=31.5)$ from various professional areas, including healthcare. With regard to the psychometric properties of the second part of this instrument, Benevides-Pereira (2007) found Cronbach's alpha values of 0.86 for $E E, 0.79$ for ED, 0.74 for $D h$, and 0.90 for PA, explaining $62.44 \%$ of the total variance of the instrument.

\section{Demographic and work questionnaire}

Questionnaire designed for this study containing information about gender, age, specialty, and number of years of residency training.

\section{Procedures}

\section{After approval of the Research Ethics} Committee of the Hospital das Clínicas da Faculdade de Medicina de Ribeirão Preto da Universidade de São Paulo (Process no 14434), the residents were individually contacted in the hospital they worked by the researcher. Those who agreed to participate in the study signed the Informed Consent form and were notified about their rights, guarantee of confidentiality in all aspects of the research process, and the purpose and procedures of the study. They self-administered instruments. In addition to signing the informed consent, participants were given the option of receiving feedback of their results in individual interviews. Thirty two out of the 305 participating residents (10.49\%) expressed interest and participated in these interviews conducted by the responsible psychologist, and referrals were made if and when necessary.

As for data analysis, at first, a descriptive statistical analysis was carried out to characterize the sample in terms of socio-demographic profile, specialty, year of residence, and repertoire of social skills. A comparative analysis was also carried out, i.e., the independent sample $t$ - test was performed to compare the means of the burnout indicators and social skills of the residents evaluated according to gender and residency year (initial years - first and second years versus final years - third-fifth years).

Subsequently, a Chi-square test was performed and Odds Ratio (OR) was computed to verify and measure the associations between burnout dimensions and social skills in the participating residents. The $O R$ results obtained in this study were interpreted according to the following: (a) $O R=1$ indicates that the presence of a satifactory repertoitre of social skills did not affect the dimension of burnout studied; (b) $O R>1$ indicates that such presence acted as a risk factor for the dimension of burnout studied; (c) $O R<1$ indicates that the presence of a satisfactory repertoire of social skills acted as a protective factor against the dimension of burnout studied.

In the data analysis, the hypothesis that the medical residents with a more elaborate repertoire of social skills would be less likely to have indicators of burnout syndrome was examined.

\section{Results}

\section{Repertoire of social skills}

Table 1 shows the characteristics of the profile of the medical residents in terms of the repertoire of social skills according to the IHS total and factor scores. 
Table 1

Characterization of the repertoire of social skills of the medical residents evaluated ( $N=305)$

\begin{tabular}{llcc}
\hline Factor - Repertoire of social skills & Mean & Standard Deviation & Range \\
\hline Total Score & $49.16^{*}$ & 29.97 & 99 \\
Factor 1 & $48.35^{*}$ & 27.58 & 96 \\
Factor 2 & $46.09^{*}$ & 25.83 & 97 \\
Factor 3 & $60.66^{*}$ & 32.08 & 99 \\
Factor 4 & $58.99^{*}$ & 27.60 & 99 \\
Factor 5 & $50.67^{*}$ & 23.80 & 97 \\
\hline
\end{tabular}

Note: *Percentile indicative of good repertoire of social skills in the factor.

Factor 1: Coping and self-assertion with risk; Factor 2: Self-assertion in the expression of positive affection; Factor 3: Conversation and social confidence; Factor 4: Self-exposure to strangers and new situations; Factor 5: Self-control over aggressiveness.

Table 2

Associations between the indicators of emotional exhaustion and the repertoire of social skills in the medical residents evaluated

\begin{tabular}{|c|c|c|c|c|c|c|c|c|}
\hline \multirow{2}{*}{ Factor IHS } & \multicolumn{2}{|c|}{ Presence of EE } & \multicolumn{2}{|c|}{ Absence of $\mathrm{EE}$} & \multirow{2}{*}{$\chi^{2}$} & \multirow{2}{*}{$p$} & \multirow{2}{*}{$O R$} & \multirow{2}{*}{$95 \% \mathrm{Cl}$} \\
\hline & $\mathrm{F}$ & $\%$ & $\mathrm{~F}$ & $\%$ & & & & \\
\hline \multicolumn{9}{|l|}{ Total score } \\
\hline Satisfactory & 113 & 53.55 & 71 & 75.53 & 13.124 & $p<0.001$ & 0.37 & $0.22-0.64$ \\
\hline Unsatisfactory & 98 & 46.45 & 23 & 24.47 & & & & \\
\hline \multicolumn{9}{|l|}{ Factor 1} \\
\hline Satisfactory & 118 & 55.92 & 63 & 67.02 & 3.319 & $p=0.07$ & 0.62 & $0.37-1.04$ \\
\hline Unsatisfactory & 93 & 44.08 & 31 & 32.98 & & & & \\
\hline \multicolumn{9}{|l|}{ Factor 2} \\
\hline Satisfactory & 117 & 55.45 & 66 & 70.21 & 5.905 & $p=0.01$ & 0.53 & $0.31-0.89$ \\
\hline Unsatisfactory & 94 & 44.55 & 28 & 29.79 & & & & \\
\hline \multicolumn{9}{|l|}{ Factor 3} \\
\hline Satisfactory & 137 & 64.93 & 81 & 86.17 & 14.391 & $p<0.001$ & 0.30 & $0.15-0.57$ \\
\hline Unsatisfactory & 74 & 35.07 & 13 & 13.83 & & & & \\
\hline \multicolumn{9}{|l|}{ Factor 4} \\
\hline Satisfactory & 143 & 67.77 & 76 & 80.85 & 5.494 & $p=0.02$ & 0.50 & $0.28-0.90$ \\
\hline Unsatisfactory & 68 & 32.23 & 18 & 19.15 & & & & \\
\hline \multicolumn{9}{|l|}{ Factor 5} \\
\hline Satisfactory & 130 & 61.61 & 67 & 71.28 & 2.656 & $p=0.10$ & 0.65 & $0.38-1.09$ \\
\hline Unsatisfactory & 81 & 38.39 & 27 & 28.72 & & & & \\
\hline
\end{tabular}

Note: Boldfaced values are statistically significant.

IHS: Inventário de Habilidades Sociais (Social Skills Inventory); EE: Emotional Exhaustion; $\chi^{2}$ : Qui-square; OR: Odds Ratio; Cl: Confidence Interval; F: Frequency; $\%$ : Percentage; Factor 1: Coping and self-assertion with risk; Factor 2: Self-assertion in the expression of positive affection; Factor 3: Conversation and social confidence; Factor 4: Self-exposure to strangers and new situations; Factor 5: Self-control over aggressiveness.

It was found that on average, the residents are at the percentiles that are within or above the mean in relation to their reference subgroup of the same gender, indicating a satisfactory repertoire of social skills. However, the high standard deviation values indicate a large difference between the means of the repertoires of social skills of the residents evaluated, which can be verified by the variance obtained.
With regard to the comparative analysis of the residents evaluated according to gender and residency years, there was a statistically significant difference only in factor 4 - self-exposure to strangers and new situations for the male residents with a mean social skills percentile score $(M=63.00$; $S D=28.72$ ) higher than the mean percentile score $(M=54.62, S D=25.72)$ of the female residents $(t=8.38, p<0.01)$. 
Burnout: associations between indicators of EE and social skills

Table 2 shows the results of the associations between the indicators of $E E$ and the repertoire of social skills in the medical residents evaluated.

Significant associations were identified between the indicators of $\mathrm{EE}$ and the total score and the following factor scores: self-assertion in the expression of positive affection, conversation and social confidence, and self-exposure to strangers and new situations. These data suggest that having a satisfactory repertoire of social skills in these factors acted as protection against the presence of $\mathrm{EE}$ indicators $(O R<1)$, i.e., residents with a satisfactory repertoire of social skills in these factors were significantly less likely to have problems regarding this burnout dimension.

In the comparative analysis, no differences were identified in the EE mean values between the residents evaluated according to gender $(t=1.88$; $p=0.06)$ and residency year $(t=1.35 ; p=0.18)$.

\section{Burnout: associations between indicators of ED and social skills}

Table 3 shows the results of the associations between the indicators of ED and the repertoire of social skills in the medical residents evaluated.

Significant associations were identified between the indicators of ED and the total score of social skills and all factor scores evaluated using the IHS. These data suggest that that residents with a satisfactory repertoire of social skills were significantly less likely to have indicators of ED, indicating a protective relationship $(O R<1)$.

There were no differences in the ED mean values between the residents evaluated according to gender $(t=0.45 ; p=0.66)$ and residency year $(t=0.49 ; p=0.62)$.

Table 3

Associations between the indicators of emotional detachment and the repertoire of social skills in the medical residents evaluated

\begin{tabular}{|c|c|c|c|c|c|c|c|c|}
\hline \multirow{2}{*}{ Factor IHS } & \multicolumn{2}{|c|}{ Presence of ED } & \multicolumn{2}{|c|}{ Absence of ED } & \multirow{2}{*}{$\chi^{2}$} & \multirow{2}{*}{$p$} & \multirow{2}{*}{$O R$} & \multirow{2}{*}{$95 \% \mathrm{Cl}$} \\
\hline & $\mathrm{F}$ & $\%$ & $\mathrm{~F}$ & $\%$ & & & & \\
\hline \multicolumn{9}{|l|}{ Total score } \\
\hline Satisfactory & 115 & 53.00 & 69 & 78.41 & 16.896 & $p<0.001$ & 0.31 & $0.17-0.55$ \\
\hline Unsatisfactory & 102 & 47.00 & 19 & 21.59 & & & & \\
\hline \multicolumn{9}{|l|}{ Factor 1} \\
\hline Satisfactory & 119 & 54.84 & 62 & 70.45 & 6.328 & $p=0.01$ & 0.51 & $0.30-0.86$ \\
\hline Unsatisfactory & 98 & 45.16 & 26 & 29.55 & & & & \\
\hline \multicolumn{9}{|l|}{ Factor 2} \\
\hline Satisfactory & 120 & 55.30 & 63 & 71.59 & 6.924 & $p<0.01$ & 0.49 & $0.29-0.84$ \\
\hline Unsatisfactory & 97 & 44.70 & 25 & 28.41 & & & & \\
\hline \multicolumn{9}{|l|}{ Factor 3} \\
\hline Unsatisfactory & 73 & 33.64 & 14 & 15.91 & & & & \\
\hline \multicolumn{9}{|l|}{ Factor 4} \\
\hline Satisfactory & 147 & 67.74 & 72 & 81.82 & 6.127 & $p=0.01$ & 0.47 & $0.25-0.86$ \\
\hline Unsatisfactory & 70 & 32.26 & 16 & 18.18 & & & & \\
\hline \multicolumn{9}{|l|}{ Factor 5} \\
\hline Satisfactory & 131 & 60.37 & 66 & 75.00 & 5.860 & $p=0.01$ & 0.51 & $0.29-0.88$ \\
\hline Unsatisfactory & 86 & 39.63 & 22 & 25.00 & & & & \\
\hline
\end{tabular}

Note: Boldfaced values are statistically significant.

IHS: Inventário de Habilidades Sociais (Social Skills Inventory); ED: Emotional Detachment; $\chi^{2}$ : Qui-square; OR: Odds Ratio; Cl: Confidence Interval; F: Frequency; $\%$ : Percentage; Factor 1: Coping and self-assertion with risk; Factor 2: Self-assertion in the expression of positive affection; Factor 3: Conversation and social 
Burnout: associations between indicators of Dh and social skills

Table 4 shows the results of the associations between the indicators of $\mathrm{Dh}$ and the repertoire of social skills in the medical residents evaluated.

Significant associations were identified only in terms of the total score, and the residents with a satisfactory total score of social skills were significantly less likely to have to have indicators of $\mathrm{Dh}$, indicating a protective relationship $(O R<1)$.

In the comparative analysis, no differences were identified in the dimension Dh between the residents evaluated according to gender ( $t=1.52$; $p=0.13)$ and residency year $(t=0.38 ; p=0.70)$.

\section{Burnout: associations between indicators of PA and social skills}

Table 5 shows the results of the associations between the indicators of PA and the repertoire of social skills in the medical residents evaluated.
Significant associations were identified between the indicators of PA and the following factor scores: self-assertion in the expression of positive affection and conversation and social confidence. These data suggest that having a satisfactory repertoire of social skills in these factors acted as protection against the presence of PA indicators $(O R<1)$.

There were no differences in the PA mean values between the residents evaluated according to gender $(t=0.03 ; p=0.98)$, but first- and second year residents had PA values $(M=14.46, S D=4.03)$ lower than those of third-fifth year residents $(M=15.59 ; S D=3.58)(t=2.58, p=0.01)$.

\section{Discussion}

The research hypothesis that the medical residents with a more elaborate repertoire of social skills would be less likely to have indicators of burnout syndrome was confirmed. All social skill

Table 4

Associations between the indicators of dehumanization and the repertoire of social skills in the medical residents evaluated

\begin{tabular}{|c|c|c|c|c|c|c|c|c|}
\hline \multirow{2}{*}{ Factor IHS } & \multicolumn{2}{|c|}{ Presence of Dh } & \multicolumn{2}{|c|}{ Absence of Dh } & \multirow{2}{*}{$\chi^{2}$} & \multirow{2}{*}{$p$} & \multirow{2}{*}{ OR } & \multirow{2}{*}{$95 \% \mathrm{Cl}$} \\
\hline & $\mathrm{F}$ & $\%$ & $F$ & $\%$ & & & & \\
\hline \multicolumn{9}{|l|}{ Total score } \\
\hline Satisfactory & 85 & 52.80 & 99 & 68.75 & 8.085 & $p<0.01$ & 0.51 & $0.32-0.81$ \\
\hline Unsatisfactory & 76 & 42.20 & 45 & 31.25 & & & & \\
\hline \multicolumn{9}{|l|}{ Factor 1} \\
\hline Unsatisfactory & 70 & 43.48 & 54 & 37.50 & & & & \\
\hline \multicolumn{9}{|l|}{ Factor 2} \\
\hline Satisfactory & 92 & 57.14 & 91 & 63.19 & 1.160 & $p=0.28$ & 0.78 & $0.49-1.23$ \\
\hline Unsatisfactory & 69 & 42.86 & 53 & 36.81 & & & & \\
\hline \multicolumn{9}{|l|}{ Factor 3} \\
\hline Unsatisfactory & 50 & 31.06 & 37 & 25.69 & & & & \\
\hline \multicolumn{9}{|l|}{ Factor 4} \\
\hline Satisfactory & 110 & 68.32 & 109 & 75.69 & 2.040 & $p=0.15$ & 0.69 & $0.42-1.15$ \\
\hline Unsatisfactory & 51 & 31.68 & 35 & 24.31 & & & & \\
\hline \multicolumn{9}{|l|}{ Factor 5} \\
\hline Satisfactory & 98 & 60.87 & 99 & 68.75 & 2.064 & $p=0.15$ & 0.71 & $0.44-1.13$ \\
\hline Unsatisfactory & 63 & 39.13 & 45 & 31.25 & & & & \\
\hline
\end{tabular}

Note: Boldfaced values are statistically significant.

IHS: Inventário de Habilidades Sociais (Social Skills Inventory); Dh: Dehumanization; $\chi^{2}$ : Qui-square; OR: Odds Ratio; CI: Confidence Interval; F: Frequency; \%: Percentage; Factor 1: Coping and self-assertion with risk; Factor 2: Self-assertion in the expression of positive affection; Factor 3: Conversation and social confidence; Factor 4: Self-exposure to strangers and new situations; Factor 5: Self-control over aggressiveness. 
Table 5

Associations between the indicators of professional accomplishment (PA) and the repertoire of social skills in the medical residents evaluated

\begin{tabular}{|c|c|c|c|c|c|c|c|c|}
\hline \multirow{2}{*}{ Factor IHS } & \multicolumn{2}{|c|}{ Presence of PA } & \multicolumn{2}{|c|}{ Absence of PA } & \multirow{2}{*}{$\chi^{2}$} & \multirow{2}{*}{$p$} & \multirow{2}{*}{$O R$} & \multirow{2}{*}{$95 \% \mathrm{Cl}$} \\
\hline & $\mathrm{F}$ & $\%$ & $\mathrm{~F}$ & $\%$ & & & & \\
\hline \multicolumn{9}{|l|}{ Total score } \\
\hline Satisfactory & 18 & 50.00 & 166 & 61.71 & 1.819 & $p=0.18$ & 0.62 & $0.31-1.25$ \\
\hline Unsatisfactory & 18 & 50.00 & 103 & 38.29 & & & & \\
\hline \multicolumn{9}{|l|}{ Factor 1} \\
\hline Satisfactory & 19 & 52.78 & 162 & 60.22 & 0.729 & $p=0.39$ & 0.74 & $0.37-1.48$ \\
\hline Unsatisfactory & 17 & 47.22 & 107 & 39.78 & & & & \\
\hline \multicolumn{9}{|l|}{ Factor 2} \\
\hline Satisfactory & 12 & 33.33 & 171 & 63.57 & 12.094 & $p<0.01$ & 0.29 & $0.14-0.60$ \\
\hline Unsatisfactory & 24 & 66.67 & 98 & 36.43 & & & & \\
\hline \multicolumn{9}{|l|}{ Factor 3} \\
\hline Satisfactory & 18 & 50.00 & 200 & 74.35 & 9.233 & $p<0.01$ & 0.34 & $0.17-0.70$ \\
\hline Unsatisfactory & 18 & 50.00 & 69 & 25.65 & & & & \\
\hline \multicolumn{9}{|l|}{ Factor 4} \\
\hline Satisfactory & 23 & 63.89 & 196 & 72.86 & 1.263 & $p=0.26$ & 0.66 & $0.32-1.37$ \\
\hline Unsatisfactory & 13 & 36.11 & 73 & 27.14 & & & & \\
\hline \multicolumn{9}{|l|}{ Factor 5} \\
\hline Satisfactory & 20 & 55.56 & 177 & 65.80 & 1.457 & $p=0.23$ & 0.65 & $0.32-1.31$ \\
\hline Unsatisfactory & 16 & 44.44 & 92 & 34.20 & & & & \\
\hline
\end{tabular}

Note: Boldfaced values are statistically significant.

IHS: Inventário de Habilidades Sociais (Social Skills Inventory); PA: Professional accomplishment; $\chi^{2}$ : Qui-square; OR: Odds Ratio; CI: Confidence Interval; F: Frequency; \%: Percentage; Factor 1: Coping and self-assertion with risk; Factor 2: Self-assertion in the expression of positive affection; Factor 3: Conversation and social confidence; Factor 4: Self-exposure to strangers and new situations; Factor 5: Self-control over aggressiveness.

factors evaluated were significantly associated with at least one burnout dimension, and odd ratio results indicated a protective relationship.

Thus, the data obtained in the present study (carried out with medical residents) endorse the role of social skills as a potential protective factor through human development, especially with respect to the professional context.

With regard to medical professionals, our findings are in line with those of other studies carried out with Brazilian medical students, which identified negative associations between social skills and stress indicators (Furtado et al., 2003) and daytime sleepiness (Kloster et al., 2013). Although those studies were not carried out with residents, their study population (medical students) is very similar to that of the present study (medical residents), and therefore the results can be compared based on the knowledge that the chronicity of occupational stress can lead to the development of burnout syndrome (Benevides-
-Pereira, 2002) and of the association between indicators of this syndrome and sleep disorder among medical students (Pagnin et al., 2014).

Other interpersonal aspects of the medical profession have been associated with the presence or absence of burnout indicators in medical residents. The recognition that effective communication contributes to successful medical practice has been widely reported in the literature (Beckman \& Frankel, 2003; Fournier et al., 2014; Gillis, Morris, \& Ridgway, 2015). Although the present study did not specifically address the doctorpatient relationship, some skills assessed by the factors self-assertion in the expression of positive affection and conversation and social confidence include various communication skills - such as giving thanks and praise; asking questions; and participating in a conversation, keeping it flowing and ending it -, which can be useful when interacting with patients, colleagues, and supervisors. 
Some other aspects of the relationship between medical residents and their supervisors, for example little reciprocity (Prins et al., 2008) and low-frequency feedback on their performance (Ripp et al., 2011), have been associated with burnout syndrome in medical residents. Although this relationship was not the focus of the present study, some skills assessed by the factors coping and self-assertion with risk and conversation and social confidence can contribute to improve such relationships since many items in these factors involve the assessment of skills required in work relationships between superiors and subordinates.

In addition to the relationship with supervisors, aspects involved in the relationship with coworkers have also being investigated as factors associated with burnout syndrome in medical residents (Prins et al., 2008) and other professionals (Maslach et al., 2001). The skills evaluated by the factors coping and self-assertion with risk; conversation and social confidence, self-exposure to strangers and new situations, and self-control over aggressiveness include some skills that can be useful in this type of relationship, among them we can highlight - public presentations to acquaintances, disagreeing with someone in front a group of people, asking colleagues for favors, rejecting unreasonable requests, and dealing with mockery.

As for the specific associations of social skill factors with the burnout dimensions, it was found that while the dimensions EE and ED were associated with most social skills factors, the dimension Dh was significantly associated only with the IHS total score. Since the IHS items assess the frequency with which the respondent reacts in a certain way, the finding mentioned above may be due to the fact that the items related to the dimension ED of the ISB assess perceptions of attitudes of detachment towards people at work, whereas the items related to the dimension Dh assess perceptions of insensitivity and feelings of coldness and cynicism towards these people.

With regard the associations of the factors self-assertion in the expression of positive affection and conversation and social confidence with the dimension PA, although professional performance was not a subject evaluated in the present study, it can be said that since these factors involve a number of communication skills, which have been proven to improve professional practice of medicine, social skills related to these factors may have favored a better professional performance, contributing to greater PA.

With respect to the comparative analyses of the burnout dimensions, it was found that residents in the final years of the program had greater PA than that of residents in the early years of the program. However, considering that studies comparing burnout indicators in residents in the initial and final years of residency training have shown different results (Asaiag, Perotta, Martins, \& Tempski, 2010; Prins et al., 2007a) and that the cross-sectional design does not compare each resident at the different stages of training, our findings should be interpreted with caution, and further studies are needed to better understand these relationships.

As for the comparisons of the repertoire of social skills of the residents evaluated according to gender and residency year, there were significant differences only in the factor self-exposure to strangers and new situations for the male residents which had a more elaborate repertoire of social skills as compared to that of the female residents. Considering that there were no significant differences in the EE and ED mean values of the residents evaluated according to gender, it can be concluded that the associations between these skills and these burnout dimensions are not well explained by the variable gender.

The contributions of the present study include the evaluation of the association of different types of social skills with dimensions of the burnout syndrome in medical residents, considering the multidimensional nature of this syndrome. Other important contributions related to bridging the gaps identified in this topic are: the evaluation of medical residents across 41 different specialties (highlighting the wide range of these areas); the high response rate achieved, which may, to a certain extent, confirm the representativeness of the data; and the 
empirical demonstration using instruments that assess social skills as possible protective factors against the burnout syndrome in medical residents, unlike other studies that focus predominantly on the risk factors for burnout in this population (Eckleberry-Hunt et al., 2009; Prins et al., 2007b).

However, despite these significant contributions, it is important to point out some limitations of the present study. The first limitation is that the cross-sectional design did not allow the evaluation of the persistence or strategies for overcoming the problems. Moreover, it did not allow the inference of causal relationships between the variables of the study, addressing only the association between them. Another limitation is related to the use of self-report instruments; although they have been validated for the Brazilian population, they assess only the indicators of problems and social skills resources and not their diagnosis. The fact that this study was carried in a single residency center should also be considered as a limitation since it hinders a greater generalization of data.

Future studies should adopt a longitudinal design that would allow monitoring the burnout syndrome during the entire residency program and evaluating the changes in the repertoire of social skills over the years of training. It is also recommended the use of a research methodology that includes the assessment not only of the social skills of medical residents, but also their social competence in terms of their relationship with patients, colleagues, and supervisors. Multicenter studies on problems related to burnout and social skills in different hospitals and regions would also be a significant contribution, considering the rich diversity across the regions in the country. It is also suggested intervention studies that address the structural aspects of residency programs and social skills training, especially communication skills, which can help medical professionals carry out their work activities since they appear to be associated with better mental health of these professionals.

Since social skills can be learned, the data obtained can contribute to the introduction of syndrome in medical residents, which can be beneficial not only for them but also and for their patients.

\section{Contributors}

K. PEREIRA-LIMA contributed to the conception and design of this study, data gathering and analysis, manuscript writing, and critical revision and approval of the final version. S.R. LOUREIRO contributed to the conception and design of this study, data analysis, manuscript writing, and critical revision and approval of the final version.

\section{References}

Asaiag, P. E., Perotta, B., Martins, M. D. A., \& Tempski, P. (2010). Avaliação da qualidade de vida, sonolência diurna e burnout em médicos residentes. Revista Brasileira de Educação Médica, 34(3), 422-429. https:// doi.org/10.1590/S0100-55022010000300012

Bandeira, M., Costa, M. N., Del Prette, Z. A. P., Del Prette, A., \& Grek-Carneiro, E. (2000). Qualidades psicométricas do Inventário de Habilidades Sociais (IHS): estudo sobre a estabilidade temporal e a validade concomitante. Estudos de Psicologia (Natal), 5(2), 401-419. https://doi.org/10.1590/S1413-294X2000000 200006

Barreto, M. C. M., Del Prette, Z. A. P., \& Del Prette, A. (1998). Análise de itens e da estrutura fatorial de um inventário para avaliação de repertório de habilidades sociais. Revista Brasileira de Estatística, 59(212), 7-24.

Beckman, H. B., \& Frankel, R. M. (2003). Training practitioners to communicate effectively in cancer care: It is the relationship that counts. Patient Education and Counseling, 50(1), 85-89. https://doi.org/10.1016/50 738-3991(03)00086-7

Benevides-Pereira, A. M. T. (2002). Burnout: o processo de adoecer pelo trabalho. In A. M. T. Benevides-Pereira (Ed.), Burnout: quando o trabalho ameaça o bem-estar do trabalhador (pp.21-92). São Paulo: Casa do Psicólogo.

Benevides-Pereira, A. M. T. (2007). Análise do ISB: Inventário da Síndrome de Burnout. Recuperado em fevereiro 6, 2014, de https://gepeb.wordpress.com/isb/

Bolsoni-Silva, A. T., Loureiro, S. R., Rosa, C. F., \& Oliveira, M. C. F. A. (2010). Caracterização das habilidades sociais de universitários. Contextos Clínicos, 3(1), 62-75. https://doi.org/10.4013/ctc.2010.31.07

Carneiro, R. S., \& Falcone, E. M. O. (2013). O desenvolvimento das habilidades sociais em idosos e sua relação na satisfação com a vida. Estudos de Psicologia (Natal), 
18(3), 517-526. https://doi.org/10.1590/\$1413-29 4X2013000300012

Cia, F., \& Barham, E. J. (2009). Social skills repertory, behavioral problems, self-concept and academic performance among children in their early school years. Estudos de Psicologia (Campinas), 26(1), 45-55. https:// doi.org/10.1590/S0103-166X2009000100005

Del Prette, Z. A. P., \& Del Prette, A. (2001). Inventário de Habilidades Sociais (IHS-Del-Prette): manual de aplicação, apuração e interpretação. São Paulo: Casa do Psicólogo.

Del Prette, Z. A. P., \& Del Prette, A. (2013). Social Skills Inventory (SSI-Del-Prette): Characteristics and studies in Brazil. In F. D. L. Osório (Ed.), Social anxiety disorder: From research to practice (pp.47-62). Hauppauge: Nova Science Publishers.

Doolittle, B. R., \& Windish, D. M. (2015). Correlation of burnout syndrome with specific coping strategies, behaviors, and spiritual attitudes among interns at Yale University, New Haven, USA. Journal of Educational Evaluation for Health Professions, 12, 41. https://doi. org/10.3352/jeehp.2015.12.41

Dyrbye, L., \& Shanafelt, T. (2016). A narrative review on burnout experienced by medical students and residents. Medical Education, 50(1), 132-149. https:// doi.org/10.1111/medu.12927

Eckleberry-Hunt, J., Lick, D., Boura, J., Hunt, R., Balasubramaniam, M., Mulhem, E., \& Fisher, C. (2009). An exploratory study of resident burnout and wellness. Academic Medicine, 84(2), 269-277. https://doi.org/ 10.1097/ACM.0b013e3181938a45

Fournier, J. P., Escourrou, B., Dupouy, J., Bismuth, M., Birebent, J., Simmons, R., ... Oustric, S. (2014). Identifying competencies required for medication prescribing for general practice residents: A nominal group technique study. BMC Family Practice, 15, 139. https://doi.org/ 10.1186/1471-2296-15-139

Furtado, E. S., Falcone, E. M. O., \& Clark, C. (2003). Avaliação do estresse e das habilidades sociais na experiência acadêmica de estudantes de medicina de uma universidade do Rio de Janeiro. Interação em Psicologia, 7(2), 43-51. https://doi.org/10.5380/psi.v7i2. 3222

Gillis, A. E., Morris, M. C., \& Ridgway, P. F. (2015). Communication skills assessment in the final postgraduate years to established practice: A systematic review. Postgraduate Medical Journal, 91(1071), 13-21. https://doi.org/10.1136/postgrad medj-2014-132772

Hohendorff, J. V., Couto, M. C. P. P., \& Prati, L. E. (2013). Social skills in adolescence: Psychopathology and sociodemographic variables. Estudos de Psicologia (Campinas), 30(2), 151-160. https://doi.org/10.15 90/ S0103-166X2013000200001

Jennings, M. L., \& Slavin, S. J. (2015). Resident wellness matters: Optimizing resident education and wellness through the learning environment. Academic Medicine, 90(9), 1246-1250. https://doi.org/10.1097/ acm.0000000000000842

Kloster, M. C., Perotta, B., Hauer, A. J., Paro, H. B. M. S., \& Tempski, P. (2013). Sonolência diurna e habilidades sociais em estudantes de medicina. Revista Brasileira de Educação Médica, 37(1), 103-109. https://doi.org/ 10.1590/S0100-55022013000100015

Lebensohn, P., Dodds, S., Benn, R., Brooks, A. J., Birch, M., Cook, P., ... Maizes, V. (2013). Resident wellness behaviors: Relationship to stress, depression, and burnout. Family Medicine, 45(8), 541-549.

Mariños, A., Otero, M., Málaga, G., \& Tomateo, J. (2011). Coexistencia de síndrome de burnout y síntomas depresivos en médicos residentes: Estudio descriptivo transversal en un hospital nacional de Lima. Revista Medica Herediana, 22(4), 159-160. Recuperado em junho 8, 2012 de http://www.scielo.org.pe/scielo. php?script=sci_arttext $\&$ pid $=$ S1018-130X2011000 400003\&nrm=iso

Maslach, C., Schaufeli, W. B., \& Leiter, M. P. (2001). Job burnout. Annual Review of Psychology, 52, 397-422. http://dx.doi.org/10.1146/annurev.psych.52.1.397

Oliveira Júnior, G. S., Chang, R., Fitzgerald, P. C., Almeida, M. D., Castro-Alves, L. S., Ahmad, S., \& McCarthy, R. J. (2013). The prevalence of burnout and depression and their association with adherence to safety and practice standards: A survey of United States anesthesiology trainees. Anesthesia \& Analgesia, 117(1), 182-193. https://doi.org/10.1213/ANE.0b0 $13 e 3182917 d a 9$

Pagnin, D., Queiroz, V., Carvalho, Y. T., Dutra, A. S., Amaral, M. B., \& Queiroz, T. T. (2014). The relation between burnout and sleep disorders in medical students. Academic Psychiatry, 38(4), 438-444. https:// doi.org/10.1007/s40596-014-0093-z

Pereira-Lima, K., \& Loureiro, S. R. (2015). Burnout, anxiety, depression, and social skills in medical residents. Psychology, Health and Medicine, 20(3), 353-362. https://doi.org/10.1080/13548506.2014.936889

Prins, J. T., Gazendam-Donofrio, S. M., Dillingh, G. S., van de Wiel, H. B., van der Heijden, F. M., \& HoekstraWeebers, J. E. (2008). The relationship between reciprocity and burnout in Dutch medical residents. Medical Education, 42(7), 721-728. https://doi.org/ 10.1111/j.1365-2923.2008.03041.x

Prins, J. T., Gazendam-Donofrio, S. M., Tubben, B. J., van der Heijden, F. M., van de Wiel, H. B., \& HoekstraWeebers, J. E. (2007a). Burnout in medical residents: A review. Medical Education, 41(8), 788-800. https:// doi.org/10.1111/j.1365-2923.2007.02797.x

Prins, J. T., Hoekstra-Weebers, J. E., van de Wiel, H. B., Gazendam-Donofrio, S. M., Sprangers, F., Jaspers, F. C., \& van der Heijden, F. M. (2007b). Burnout among 
Dutch medical residents. International Journal of Behavavioral Medicine, 14(3), 119-125. https://doi. org/10.1007/BF03000182

Prins, J. T., van der Heijden, F. M., Hoekstra-Weebers, J. E., Bakker, A. B., van de Wiel, H. B., Jacobs, B., \& Gazendam-Donofrio, S. M. (2009). Burnout, engagement and resident physicians' self-reported errors. Psychology, Health and Medicine, 14(6), 654-666. https://doi.org/10.1080/13548500903311554

Ripp, J., Babyatsky, M., Fallar, R., Bazari, H., Bellini, L., Kapadia, C., ... Korenstein, D. (2011). The incidence and predictors of job burnout in first-year internal medicine residents: A five-institution study. Academic Medicine, 86(10), 1304-1310. https://doi.org/10. 1097/ACM.0b013e31822c1236

Shanafelt, T. D., Bradley, K. A., Wipf, J. E., \& Back, A. L. (2002). Burnout and self-reported patient care in an internal medicine residency program. Annals of Internal Medicine, 136(5), 358-367. https://doi.org/10.7326/0 003-4819-136-5-200203050-00008

Soares, A. B., Francischetto, V., Peçanha, A. P. C. L., Miranda, J. M., \& Dutra, B. M. S. (2013). Intelligence and social competence in university adaptation. Estudos de Psicologia (Campinas), 30(3), 317-328.
https://doi.org/10.1590/S0103-166X201300030 0001

Thomas, N. K. (2004). Resident burnout. Journal of the American Medical Association, 292(23), 2880-2889. https://doi.org/10.1001/jama.292.23.2880

van der Heijden, F., Dillingh, G., Bakker, A., \& Prins, J. (2008). Suicidal thoughts among medical residents with burnout. Archives of Suicide Research, 12(4), 344-346. https://doi.org/10.1080/1381111080232 5349

West, C. P., Shanafelt, T. D., \& Kolars, J. C. (2011). Quality of life, burnout, educational debt, and medical knowledge among internal medicine residents. Journal of the American Medical Association, 306(9), 952-960. https://doi.org/10.1001/jama.2011.1247

West, C. P., Tan, A. D., Habermann, T. M., Sloan, J. A., \& Shanafelt, T. D. (2009). Association of resident fatigue and distress with perceived medical errors. Journal of the American Medical Association, 302(12), 1294-1300. https://doi.org/10.1001/jama.2009.1389

Received: December 15, 2015

Final version: May 31, 2016

Approved: June 29, 2016 